\title{
TEORIZANDO A DINÂMICA DA ESTABILIDADE E DA MUDANÇA NAS ORGANIZAÇÕES
}

Silvio Eduardo Alvarez Candido seacandido@dep.ufscar.br Doutorando em Engenharia da Produção pelo Departamento de Engenharia de Produção, Universidade Federal de São Carlos São Carlos - SP, Brasil

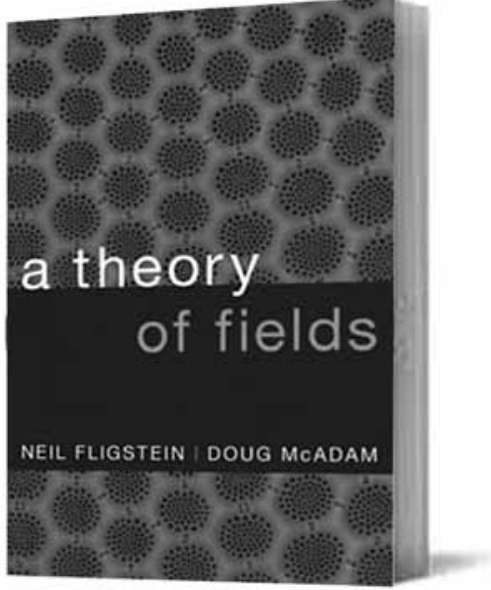

\section{A THEORY OF FIELDS}

De Neil Fligstein e Doug McAdam. New York: Oxford University, 2012. $238 \mathrm{p}$.

A teoria dos Campos de Ação Estratégica (CAE), desenvolvida por Niel Fligstein e Doug McAdam, é apresentada neste livro recentemente lançado, fruto de uma longa cooperação iniciada quando os autores foram colegas no Departamento de Sociologia da Universidade do Arizona. O trabalho parte da verificação da necessidade de teorização da dinâmica da estabilidade e da mudança em espaços sociais de nível meso para explicar "verdades fundamentais sobre a vida social". Baseada, sobretudo, na sociologia de Pierre Bourdieu, nas abordagens neoinstitucionalistas da análise organizacional e nas teorias dos movimentos sociais, a teoria dos CAE apresenta um referencial integrado para explicar a ação coletiva na sociedade.

Parte-se da ideia de que a atividade simbólica colaborativa, na qual identidades e significados são compartilhados entre os indivíduos, consiste no fundamento da sociabilidade. Com base em literatura histórica e arqueológica, os autores propõem que são a capacidade e a necessidade autoconsciente de organização de grupos para a ação com fins coletivos que distinguem o homem como um ser social. Inspirados em trabalhos anteriores de Fligstein, buscam incorporar essa concepção de agência como microfundação do arcabouço analítico e conceitual por meio da ideia de habilidades sociais, definida como a habilidade dos atores do campo de assumirem a perspectiva dos outros para induzir a cooperação.

Como em outras abordagens de campo, há, basicamente, dois grupos de atores. Os atores incumbentes são mais bem posicionados, com o domínio de maior quantidade de recursos e com suas visões e interesses influenciando fortemente os propósitos do campo e a forma como ele se organiza. Os desafiantes contam com menor influência sobre a dinâmica social, tendo, frequentemente, que se submeter a sua lógica para sobreviver. Assim, nos campos, as instituições estão diretamente relacionadas à configuração de poder e, uma vez que as posições se definem, há uma tendência de estabilização do espaço, com os sentidos e regras favorecendo os dominantes.

Fligstein e McAdam dedicam o terceiro capítulo para mostrar as macroimplicações de sua teoria. Buscam evitar uma abordagem "campocêntrica", partindo da ideia de que os campos são como "bonecas russas", com um CAE formando e sendo formado por outros. Destacam, ainda, que a relação entre esses espaços relativamente autônomos pode ser de três tipos. Em um primeiro caso, campos podem manter relações hierárquicas, em que um campo depende de outro. Os espaços podem, ainda, ser mais cooperativos e recíprocos, condições que tendem a se desenvolver quando não existem grandes assimetrias de recursos. Por último, os CAE podem ser distantes ou próximos, dependendo da densidade dos vínculos mantidos entre seus integrantes. Campos Estatais são apre- 
sentados como componente-chave do macroambiente, considerados, por si só, um sistema com diversos subcampos. Os autores apresentam, também, sua visão sobre o papel da burocratização, das unidades de governança e dos sistemas de educação superior e das profissões para a compreensão do enraizamento dos CAE.

No capítulo quatro do livro, é apresentado o aspecto central da teoria, que consiste na teorização da dinâmica de estabilidade e da mudança. Propõe-se que a compreensão e análise dos campos dependem da identificação do estado em que eles se encontram, descrevendo quatro estados possíveis.

Campos emergentes são espaços pouco institucionalizados, em que os significados, a construção das identidades e formas de organização estão em disputa. Surgem por meio de processos de mobilização, nos quais, com base em uma leitura da realidade e de percepções de oportunidades e desafios, os atores desenvolvem novas interações, traçando seus contornos. A atuação dos atores socialmente hábeis, dos atores estatais e o surgimento de unidades internas de governança são fundamentais nesse momento, promovendo a superação da situação de caos inicial.

A emergência dos CAE tende a ser seguida por momentos de estabilidade, o segundo estado destacado, em que os arranjos estabelecidos se institucionalizam. Apesar de os campos serem sistematicamente reproduzidos nessa situação, eles não são estáticos e caracterizam-se por uma dinâmica constante de mudanças incrementais. Conduzidos por seus atores socialmente hábeis, grupos dominantes buscam manter ou melhorar sua posição e os desafiantes atuam de uma posição bem mais desconfortável, utilizando-se de táticas como as alianças com grupos de outros CAE ou o afastamento do confronto direto com os incumbentes.

Mas os campos não estão fadados a se reproduzir ou sofrer apenas mudanças incrementais, sendo o terceiro estado descrito pelos autores o de crise. Para os autores, a maioria das crises nos CAE é decorrente de choques exógenos, gerados em outros campos, que constituem ambiente mais amplo. Esses choques podem gerar alterações nas percepções de realidade de grupos dominantes e desafiantes, fazendo com que enxerguem ameaças e oportunidades para a realização de seus interesses. Com base nessa leitura, ocorrem processos de mobilização emergente, e os atores engajam-se em ações inovadoras, gerando momentos de contenção. Mudanças devidas às dinâmicas internas ocorrem como consequência das disputas e alterações pequenas e constantes no comportamento dos atores.

É na interação entre incumbentes e desafiantes nos momentos de crise que novas ordens se constroem, sendo esses processos semelhantes aos recorrentes no momento de emergência dos CAE, com a diferença de que os atores já possuem referências claras sobre a configuração do campo. Em geral, os dominantes mantêm uma postura conservadora, buscando preservar as fontes culturais e políticas de suas vantagens, com apoio de aliados e das estruturas de governança. Já os desafiantes buscam forjar coalizões vencedoras e agem conforme uma visão compartilhada de como o campo pode vir a ser organizado.

A perspectiva dos CAE é ilustrada de maneira sintética no livro, por meio de dois casos anteriormente estudados pelos autores: o das disputas raciais nos Estados Unidos e o do surgimento e degradação da indústria de seguros das hipotecas no mesmo país.
Finalizando o trabalho, os autores apresentam considerações metodológicas para o estudo dos CAE, apresentando um roteiro que pode ser aplicado em pesquisas que adotem tanto métodos positivistas quanto realistas.

Diferenças importantes da teoria apresentada por Fligstein e McAdam em relação a abordagens análogas podem ser destacadas. Comparando sua teoria com as abordagens de campo do novo institucionalismo na análise organizacional, destaca-se a maior ênfase em aspectos relativos aos interesses, ao poder e à mudança institucional. $\mathrm{O}$ arcabouço analítico e conceitual embutido no conceito de campo é, ainda, mais completo que o das abordagens de análises de redes, que, na visão dos autores, são excessivamente empíricas, o que não os desqualifica como poderosos instrumentos metodológicos. Comparada à abordagem bourdiesiana, verifica-se uma ênfase mais sistemática na ação coletiva, possibilitada graças ao diálogo com as teorias dos movimentos sociais e das organizações.

A teoria dos campos desenvolvida pelos autores corresponde a uma contribuição importante para os estudos organizacionais, sendo sua leitura amplamente recomendada. Assumindo a complexa tarefa de integrar corpos teóricos distintos, a obra sugere um programa colaborativo de pesquisa sobre campos, mas é a aplicação do referencial teórico em pesquisas empíricas que poderá evidenciar sua real contribuição para uma compreensão da dinâmica da estabilidade e da mudança nas organizações. Somente assim, será possível avaliar o alcance desta obra de tom escolástico, que ainda carece de evidências empíricas que ilustrem sistematicamente suas amplas proposições teóricas. 